\title{
La ficción audiovisual y cibernética de los anunciantes. Estudio de caso de Cómo conocí a vuestra Amatxu
}

MHCJ no 7 | Año 2016

Artículo no 2 (74)

Páginas 31 a 51

mhjournal.org
Dr. Jesús Segarra-Saavedra| jesus.segarra@ua.es

Universidad de Alicante

Dra. Tatiana Hidalgo-Marí | tatianahidalgomari@gmail.com Universidad de Alicante

\section{Palabras clave}

Marketing de contenidos; ficción online; Internet; marca; webserie.

\section{Sumario}

1. Introducción 2. Del branded content a la branded webserie 2.1. Aproximación teórica a la fórmula del branded content 2.2. Branded content en el contexto ficcional 3. Branded webserie: entre la ficción web y el marketing de contenidos 3.1. Branded webserie en clave española 4. Análisis de caso: Cómo conocí a vuestra Amatxu 4.1. Metodología 4.2. Sobre la campaña 4.3. La webserie: Cómo conocí a vuestra Amatxu 5. Conclusiones 6. Referencias bibliográficas 7. Notas

\section{Resumen}

Las webseries se posicionan, cada vez más, como un gran fenómeno narrativo en el contexto audiovisual de internet. Este producto de ficción, creado para ser difundido en la web, se caracteriza por ser un formato que en principio asegura su éxito, gracias al carácter de entretenimiento de sus contenidos, su corta duración y la facilidad para fidelizar audiencias. La accesibilidad e interconectividad de internet, además, convierte a las series online en productos narrativos muy consumidos por el espectador digital.

El éxito de las webseries, unido a la tendencia de las marcas y corporaciones por generar contenidos de entretenimiento con los que relacionarse directamente con sus públicos, genera un panorama estratégico en el que cada vez son más los anunciantes que apuestan por el branded content vinculado a las webseries.

Esta comunicación pretende aproximar las estrategias del brand content al fenómeno de las webseries españolas. Para ello realiza un recorrido por los ejemplos de branded content y webseries más emblemáticos de producción española, con el fin de establecer los orígenes y casos de éxito de dicha alianza. Tras el recorrido contextual, el presente trabajo se centra en el estudio de caso de la webserie Cómo conocí a vuestra Amatxu producida por Social Noise para la marca Pacharán Zoco. A través del método cualitativo que recoge las vinculaciones de la campaña con la marca, se analiza el despliegue transmedia que ha apoyado a la ficción en sí y al resto de acciones creadas alrededor de la webserie, tanto en páginas webs como en Redes Sociales.

El estudio pone de manifiesto la relevancia de la ficción y el entretenimiento online en el seno de las estrategias del marketing de contenidos. Se trata de historias que los anunciantes nos cuentan para hacernos llegar los valores de la marca, relatos audiovisuales y branded storytelling en los que las marcas se expresan, definen y comunican. Y lo hacen en un contexto digital, heterogéneo y multipantalla que convierte a la webserie en un recurso de promoción estratégica para las marcas.

\section{Forma de citar este artículo en las bibliografías}

Jesús Segarra-Saavedra, Tatiana Hidalgo-Marí (2016): "La ficción audiovisual y cibernética de los anunciantes.

Estudio de caso de Cómo conocí a vuestra Amatxu”, en Miguel Hernández Communication Journal, nº páginas 31 a 51. Universidad Miguel Hernández, UMH (Elche-Alicante). Recuperado el__ de de 20__de: @ink del 


\section{The audiovisual and cybernetic fiction advertisers. Case Study of How I Met Your Amatxu}

\author{
MHCJ no 7 | Año 2016 \\ Artículo no 2 (74) \\ Páginas 31 a 51 \\ mhjournal.org
}

\author{
Dr. Jesús Segarra-Saavedra| jesus.segarra@ua.es \\ Universidad de Alicante \\ Dra. Tatiana Hidalgo-Marí | tatianahidalgomari@gmail.com \\ Universidad de Alicante
}

Keywords

Branded content; online fiction; Internet; brand; webseries.

\section{Summary}

1. Introduction 2. From branded content to branded webserie 2.1. theoretical approach to the formulation of branded content 2.2. Branded content in the fictional context 3. Branded webserie: between fiction and web content marketing 3.1. Branded webserie in Spanish key 4. Case Analysis: How I Met Your Amatxu 4.1. Methodology 4.2. About 4.3 campaign. The web series: How I Met Your Amatxu 5. Conclusions 6. References 7. Notes

\begin{abstract}
Webseries are positioned, increasingly, as the big narrative phenomenon on audiovisual and internet context. This fictional product created to be broadcast on the web, is characterized as a format that ensures your success, thanks to the character of entertainment content, its short duration and ease of loyal audiences. Accessibility and interconnectivity of internet, as well as, makes the online series in very consumed narrative by digital viewer.
\end{abstract}

The success of the webseries, coupled with the tendency of corporations to generate entertainment contents which relate directly with the audience, generates a strategic landscape in which more and more advertisers opt for the branded content linked to the webseries.

This paper aims to align the strategies of the brand content to the phenomenon of the Spanish webseries. It performs a tour of the examples of branded content and most emblematic of Spanish production webseries, in order to establish the origins and success stories of this alliance. After the shortcut path, this paper focuses on the case study of the webserie "Cómo conoci a vuestra Amatxu" (How I met your Amatxu) produced by Social Noise for Pacharán Zoco. Through a qualitative method that collects links to the campaign with the brand, we analyze the transmedia universe of the fiction and the rest of acts created around the webserie, both websites and social networks.

The study highlights the importance of fiction and entertainment online in the marketing content strategies. Stories that advertisers tell us to send us the values of the brand. Audiovisual stories and branded storytelling in which brands express, define and communicate theirs values. And they do it in a digital, heterogeneous and multiscreen context that makes the webseries a resource of strategic promotion for brands.

\section{How to cite this paper in bibliographies}

Jesús Segarra-Saavedra, Tatiana Hidalgo-Marí (2016): “La ficción audiovisual y cibernética de los anunciantes. Estudio de caso de Cómo conocí a vuestra Amatxu”, en Miguel Hernández Communication Journal, nº7, páginas 31 a 51. Universidad Miguel Hernández, UMH (Elche-Alicante). Recuperado el de de 20__ de: link del 
"Cualquiera puede buscar moda en una tienda o historia en un museo. El explorador creativo busca historia en una ferretería y moda en un aeropuerto" (Robert Wieder).

\section{Introducción}

Hablar de webseries es hacer referencia a aquellos productos seriados de ficción audiovisual creados y producidos para ser emitidos por internet. Se trata de una nueva forma de producción de ficción, dirigida a un nuevo público y emitida en un nuevo medio, que presenta características propias diferentes a las ofrecidas por las ficciones de los medios tradicionales (Hernández, 2013).

Este reciente producto audiovisual se encuentra en crecimiento constante y cada vez son más las productoras y cadenas que se lanzan a la creación y difusión online. Las conclusiones del Observatorio Internacional de la Televisión (OITVE) en el año 2010 ya afirmaban que la producción de webseries había igualado en volumen a la producción de ficciones para televisión, que había disminuido puntualmente ese año.

La ficción en general es una apuesta segura en la parrilla televisiva, hecho que ha facilitado su interés como formato de ficción web. Las webseries se apropian de las características del género televisivo y lo extrapolan a la web, modificando la relación comunicativa entre el contenido y el receptor, y renovando la narrativa televisiva mediante la incorporación de la participación activa de la audiencia, el devenir de la historia y el resto de recursos derivados del medio online (Lloret y Canet, 2008).

Según Morales y Hernández (2012) existen diversos grados de representación en las webseries: las tradicionales, que son aquellas que reproducen formalmente el estilo de la televisión tradicional; los videblogs, que son producciones basadas en una tecnología austera, el uso de la cámara estática y un protagonista-narrador que se comunica con ella y las webseries propiamente dichas, que se caracterizan por motivar una implicación de la participación del usuario en la configuración de la trama. El cambio en la recepción y las múltiples posibilidades de interacción y retroalimentación que ofrece internet representan un cambio de paradigma en el proceso comunicativo y, por ende, la transformación en la comunicación y la cultura general representan una transformación del proceso de comunicación y, por su mediación, de la cultura en general (Castells, 2001).

En este contexto de renovación en la producción audiovisual y de aprovechamiento de los recursos que ofrece el medio online, los formatos publicitarios tradicionales tienden a quedar obsoletos. La irrupción de la TDT ya supuso una de las alteraciones más significativas para la televisión, sustentado por un cambio en la forma de consumir los contenidos y por una fragmentación significativa de audiencias (Morales, 2011; Aguado, 2007; Ibáñez y Fernández, 1999). La televisión necesita adaptarse al nuevo panorama comunicativo y hacer frente a los cambios estructurales en el modo existente de producción y consumo. En este sentido: 
Los inicios han sido marcados por las propias televisoras de ámbito generalista, que han alojado contenidos en sus páginas para exhibir directamente sus programas de ficción. Dicha alternativa ha sido explotada por los nuevos productores web para crear y difundir sus productos a un coste reducido y con una audiencia potencial que era inalcanzable por las televisiones convencionales (Morales y Hernández, 2012: 141).

En este panorama de cambios en los formatos y audiencias televisivas, adquiere gran importancia el concepto de convergencia mediática (Jenkins, 2009) que hace referencia a la convivencia entre los nuevos y los viejos medios de comunicación, generando el nacimiento de una cultura colectiva y participativa alrededor de estos. Así, la convergencia mediática nos sirve para entender la innovación en la creación y desarrollo de proyectos, que dista de la unidireccionalidad de la televisión y se vuelve hacia un proceso integral mucho más colaborativo (Morales y Hernández, 2012).

Las posibilidades de la web 2.0 suponen toda una evolución tecnológica puesta al servicio del usuario, en la que los contenidos están a la merced del internauta, fruto de una necesidad de participación cultural heredada de décadas anteriores (Jenkins, 2009). Esta necesidad de la que habla Jenkins ha establecido el desarrollo y la rápida consolidación de plataformas como Youtube, que ponen la tecnología al servicio de las necesidades de la sociedad, principalmente por su vinculación a Google, el buscador imperante.

Esta subordinación de la tecnología a la sociedad en general y al usuario en particular responde a lo que Castells denominó "autocomunicación de masas", capaz de llegar a una audiencia global, alejándose de las fragmentaciones tradicionales y además permite que "uno mismo genera el mensaje, define los posibles receptores y selecciona los mensajes concretos o los contenidos de la web y de las redes de comunicación electrónica que quiere recuperar" (2001: 88).

Ante la nueva situación de convergencia mediática y los cambios estructurales en las formas de producción y consumo, la publicidad se reinventa y busca nuevas fórmulas de implicación con los públicos, para que se adapten a las nuevas lógicas y que, de alguna manera, le permitan seguir llegando a los públicos de una manera eficiente. En un contexto de saturación publicitaria (Reinares, Reinares y Reinares, 2007), en el que los medios tradicionales están en plena crisis digital y las audiencias son cada vez más heterogéneas, volátiles y exigentes, el branded content es una de las fórmulas publicitarias entendida como estrategia suculenta tanto para anunciantes y medios de comunicación, como para las propias audiencias, que se muestran receptivas a este método del contenido, del storytelling, en el que la marca deja de hablar de ella misma para contarnos historias en clave narrativa.

En este trabajo se pretende analizar el uso del branded content en el contexto de la ficción producida para internet. A través de un repaso a los casos más emblemáticos de branded content en webseries, y de un estudio de caso específico, pretende conocer la puesta en escena de una webserie diseñada, producida y difundida por la propia marca. Para ello, se analiza en profundidad la 
webserie Cómo conoci a nuestra Amatxu (2015) como ejemplo de contenido producido por la marca Pacharán Zoco con el fin de determinar las dimensiones y el alcance de la marca en el seno de este producto de ficción online, así como para establecer las posibilidades interactivas que benefician a la marca-productora mediante la aplicación del branded content.

\section{Del branded content a la branded webserie}

\subsection{Aproximación teórica a la fórmula del branded content}

La fórmula del branded content tiene sus orígenes en televisión, medio en el que ya se hacía publicidad de forma no convencional, cuestión definida como "todas aquellas tipologías de comunicación comercial en televisión diferentes del spot o anuncio convencional" (Reinares y Reinares, 2007: 181). Aunque los hermanos Reinares se refieren en cierta medida de forma exclusiva al branded content en televisión, esta forma de hacer publicidad es extensiva a todos los medios y soportes, entrando en juego la creatividad del emisor/anunciante y los objetivos específicos de la campaña.

Se trata de la inclusión de productos, servicios y marcas, con mayor o menor éxito, en obras culturales, principalmente televisivas y cinematográficas, pero también editoriales y de cualquier otra naturaleza, susceptible de captar la atención de una audiencia potencial. La integración ha pasado por distintos niveles y épocas, desde la descarada inclusión de productos hasta las sutiles presencias (Segarra e Hidalgo, 2013: 4).

Con el branded content, "la marca busca generar conversaciones" (Madinabeitia, 2010: 49), ofreciendo un contenido audiovisual que pretende transmitir sus valores. Al mismo tiempo, la fórmula fomenta la conversación e interacción entre usuarios y marca por la transmedialidad que suele motivar a las acciones de branded content (Castelló y Del Pino, 2014). Esta vinculación de marca y usuario es, al fin y al cabo, representa, la generación de un contenido cultural cuya finalidad es totalmente publicitaria (Mateos Rusillo, 2013).

Podríamos establecer la máxima del branded content como la necesidad "de ofrecer experiencia, no anuncios" Regueira (2011: 218). Se trata, al fin y al cabo, de generar escenarios de comunicación no convencional, en los que el mensaje forme parte de la narrativa de la historia. Las marcas a través del branded content son coproductoras de su propio contenido y se adaptan a las nuevas necesidades del paradigma publicitario. Gracias a sus posibilidades de atracción, las propias marcas son capaces de generar campañas exitosas sin llegar a molestar al público. Se pasa, pues, de la mera publicidad al entretenimiento basado en el contenido.

En base a lo expuesto anteriormente, podemos entender el branded content como un recurso relevante para la industria, siempre que los contenidos sean destacables para el usuario y se 
respete el equilibrio de intereses de todos los implicados en el nuevo proceso comunicativo (Del Pino, Castelló y Ramos-Soler, 2013).

\subsection{Branded content en el contexto ficcional}

Que la ficción audiovisual se ha convertido en uno de los productos culturales más demandados por la audiencia en los últimos años es evidente. Ficciones españolas como Cuéntame cómo pasó (TVE 1, 2001-) en antena desde principios del siglo XXI hasta fenómenos audiovisuales y cibernéticos internacionales como Game of Thrones (HBO, 2011-) dejan patente que las historias secuenciales contadas no sólo por televisión llegan a crear y mantener audiencias fieles. Los anunciantes se ven atraídos por sus cifras de share. El objetivo es adherirse al contenido, bien a los espacios más próximos -patrocinando su emisión en televisión mediante caretas de inicio, intermedios y salida- o bien en su interior -a través del product o brand placement- a costes asumibles sólo para anunciantes con millonarios presupuestos para publicidad o para productos, marcas o servicios que sean requeridos por el equipo de producción de la ficción.

La saturación del mercado publicitario, unido a la crisis de los medios masivos y al nuevo perfil del consumidor-espectador han exigido a la convencionalidad publicitaria que se reinvente, como respuesta a su capacidad de adaptación. El espectador rechaza cada vez más la publicidad intrusiva, más si cabe en espacios que consumimos como parte de nuestro entretenimiento. Frente a la invasión publicitaria, el espectador busca que las marcas le cuenten historias. Quieren sentirse vinculados emocionalmente a sus historias y con ellas a la marca. Desean dejarse llevar por las historias, aunque vengan narradas por una marca (Segarra e Hidalgo, 2013). La marca, pues, necesita del contenido para generar ese vínculo emocional que le permite introducirse en el campo de interés cognitivo del espectador, puesto que "un storytelling formulado sobre una marca sin contenidos es como un castillo de arena" (VV.AA., 2013).

En consonancia con esta necesidad del espectador, el branded content se ha convertido en una tendencia latente en la investigación de los últimos años. Tanto como estrategia publicitaria, como desde el punto de vista del marketing, la generación de contenidos alrededor de una marca resulta un tema suculento a la hora de entender y explicar el panorama convergente actual.

En el contexto 2.0, el branded content ha dado un paso más en su desarrollo hacia una fórmula mixta de contenido y comercial que se asienta en un contexto de cultura participativa e interacción multidireccional. El espectador de la ficción online se ha convertido en co-productor, distribuidor y consumidor de los contenidos del propio producto cultural (Bermejo, 2008), a cuya enumeración de características añadiríamos la de distribuidor, por ser un sujeto capaz de promocionar la ficción mediante sus redes sociales de comunicación virtual.

Si unimos los conceptos de branded content y webserie, el resultado final es el de branded webserie. Se trata de ficciones online que han sido desarrolladas para difundir los valores de una marca y favorecer su notoriedad principalmente, tal y como identifican Tur y Segarra (2014). 


\section{Branded webserie: entre la ficción web y el marketing de contenidos}

Siguiendo con las conclusiones del Informe Video marketing y publicidad en vídeo online: una aproximación desde la perspectiva del usuario, elaborado por el Interactive Advertising Bureau (IAB) en colaboración con Cool Insights, los usuarios de internet españoles dedican como media una de cada cuatro horas de navegación a ver contenidos de vídeo (el 35\% del tiempo en personas de 18 a 30 años) $)^{1}$.

En línea a este aumento en el consumo de vídeo online y teniendo en cuenta el cambio de paradigma comunicativo que se ha producido en los últimos años, es evidente que han proliferado las producciones audiovisuales en internet, en especial, los productos audiovisuales de ficción, es decir, las webseries.

Este nuevo formato audiovisual no dispone de un patrón estándar de clasificación y su duración, contenido y características varía en función del público al que se dirigen y a los propios objetivos de la producción. En cualquier caso, el objetivo de las webseries es crear un vínculo con el usuario mucho más interactivo que el que permite establecer la televisión comercial en la medida en que el canal principal por el que se difunden es Youtube. Además, puesto que las televisiones son cada vez menos favorables a probar nuevos formatos, la web serie emerge como una disciplina ideal para testear, afinar y lanzar los formatos ganadores de la televisión del futuro (Pujadas, 2011).

Las marcas han visto en este nuevo formato audiovisual la posibilidad de involucrarse de forma innovadora y creativa con el espectador. Por tanto han proliferado los casos en los que la propia marca es la que envuelve y desarrolla la historia narrada. De esta manera, se consigue aunar entretenimiento y ficción con publicidad, de una manera poco convencional, contando historias que resulten atractivas para el espectador y que generen ese storytelling necesario para evitar el rechazo a la marca que se venía dando con la ya archiconocida saturación de la publicidad convencional.

Por eso es tan importante el branded content, porque nos llama la atención, pero no como antes, sino con sutileza. La marca deja de ser molesta ya que no interrumpe nuestro consumo audiovisual para ofrecernos algo que, irremediablemente, nos atrae hacia ella o nos acerca a sus valores. De esta manera, el usuario-espectador da una oportunidad a la marca, cuando antaño en la publicidad tradicional llegó a rechazarla. El éxito de la marca deja de ser "el poder mágico de la imagen” (Eguizábal, 1998: 19) para convertirse en la imagen que proyecta de sí misma.

Y así, en esa lucha por introducir la marca mediante la historia, en ese ir y venir de storytellings que nos transmiten historias contadas por una marca, empezaron a proliferar ejemplos basados en el contenido. A principios del siglo XXI, BMW (2001-2002) producía la serie The Hire, compuesta 
por ocho cortos de ocho minutos de duración emitidos online, con Clive Owen como protagonista, en la que se promocionaban diversos modelos de la marca. Audi desarrolló en 2012 y en colaboración con la cadena de televisión Fox, el Untitled Jersey City Project, una serie de ocho capítulos de dos minutos de duración cada uno para promocionar el nuevo A6 de aquel año. La marca Scotch-Brite lanzó una webserie de cuatro episodios que narraba la historia de un estropajo que vive un gran viaje para seguir el rastro de su familia a lo largo del país. La campaña Cupidity de Cornetto representa una colección de pequeños cortometrajes que giran en torno al primer amor. El episodio "Cafetería Kismet" tiene más de 500.000 reproducciones en Youtube ${ }^{2}$ y ha logrado acercarse al usuario al que querían dirigirse con los componentes de felicidad y nostalgia que incorporan los guiones. Chipotle con Framed and Dangerous, Falling for you de la marca Target o The Beauty Inside de Intel y Toshiba son otros ejemplos recientes que han elevado el éxito del branded content y lo han posicionado como la estrategia de moda en cuanto a comunicación de marca online se refiere.

\subsection{Branded webserie en clave española}

Aunque los primeros ejemplos de ficción y branded content online podín verse en EE.UU. desde los últimos años del siglo XX, en España la acogida de la fórmula publicitaria fue más tardía, aunque se afincó rápidamente y se convirtió en una estrategia recurrente para anunciantes y marcas.

Fuera del ámbito publicitario, Hernández (2011) data la primera webserie española en 2004, Cálico Electrónico, que se emitió durante cinco años y fue traducida al inglés y al francés. En 2010, tras la falta de financiación de la productora, la serie dejó de emitirse.

Seguido al éxito de Cálico Electrónico, se empezó a emitir en 2006 la archiconocida Que vida más triste, suponiendo ésta el primer caso de transmedialidad inversa que saltó a la televisión generalista desde la web y fue emitida por La Sexta durante varios años. Algunos investigadores indican que fue la webserie Lo que surja (2007), la primera serie online española transmitida únicamente por internet (Lacalle, 2011: 93). Tras estas, proliferaron las series concebidas únicamente para ser consumidas en internet y surgieron muchos ejemplos que se consolidaron como emblemas de la ficción online, como Malviviendo (2008-2014). Sea como fuere:

La producción de ficción audiovisual para internet en España desde 2004 a febrero de 2011 se ha ido incrementando con una media de 10 webseries estrenadas por año. Convirtiendo la Red en una plataforma perfecta de proyección de contenidos propios de ficción. Las herramientas que facilita el medio digital ofrecen la posibilidad de crear un propio canal de televisión, como es el caso de Youtube, con una audiencia que traspasa los límites nacionales de la televisión. Y al añadir subtítulos a las producciones traspasaríamos las barreras idiomáticas (Hernández, 2011: 23).

Rápidamente las marcas vieron el potencial de este nuevo producto audiovisual y se convirtieron en abanderadas de estos contenidos online. El éxito de estas producciones permitía a la marca 
seguir aunando entretenimiento con publicidad, de la forma más directa y discreta posible, evitando así el rechazo sobrevenido a la publicidad convencional. Y siguiendo con estrategias previamente testeadas en la televisión convencional como fue, por ejemplo, I+B: Ir más a los bares, producción de ficción de Coca Cola para Telecinco, las marcas se lanzaron a la generación de contenido en la ficción online.

Así, Telefónica estrenó en 2012 Are You App?, una webserie en la que las tramas giraban en torno a las aplicaciones móviles y que contaba con un reparto en el que figuraban actores conocidos de la televisión. El Corte Inglés aplicó la fórmula del brandend content a Probando, probando, una webserie cuya trama se desarrollaba dentro de los probadores de los propios almacenes. Y Citroën estrenó Días de shopping, una producción para web en la que el director Carlos Trueba retrataba las peripecias de un grupo de amigas en sus recorridos por el barrio de Salamanca de Madrid.

Mango es otra de las marcas españolas que lleva tiempo empleando esta técnica a través de su sitio QueMePongoByMango.com, poniendo de manifiesto las posibilidades del medio online en el lanzamiento de campañas de contenido de marca. Securitas Direct desarrolló una producción seriada mediante la que enseñaba a robar casas a través de vídeos de humor en su canal de Youtube y Endesa lanzó Basket Love's, campaña en busca de los amantes del baloncesto que contó con la colaboración de jugadores internacionales. BBVA se estrenó en el campo del branded content con la webserie ¿Quieres algo más?, una comedia online de ocho capítulos dirigida a las pequeñas empresas y al gremio autónomo. Esta narra las peripecias cotidianas de un grupo de trabajadores autónomos que compartían asesora fiscal. Esta producción ha sido una de las webseries con contenido de marca que más éxito ha generado en su primer capítulo, siendo trending topic en Twitter durante casi 20 horas el mismo día de su lanzamiento online ${ }^{3}$. El caso más innovador más reciente, probablemente, ha sido el lanzamiento de la micro serie \#XQEsperar producida por la marca de aperitivos Risi y que se puede considerar una ficción diseñada desde el transmedia propiamente dicho, en tanto en cuanto ha contado con emisiones en televisión (Atresmedia) como en internet (Atresplayer y el canal de Youtube de Risi) y paralelamente con participación en Facebook y Twitter ${ }^{4}$.

\section{Análisis de caso: Cómo conocí a vuestra Amatxu}

\subsection{Metodología}

El estudio que presentamos se enmarca en un contexto de análisis de marca publicitaria desde la perspectiva del branded content. Para ello, se ha seleccionado un caso concreto de webserie que ha sido realizado exclusivamente para el beneficio de la imagen corporativa de la marca. La selección ha sido únicamente mediante el juicio del investigador y conlleva un análisis cualitativo del tratamiento de la marca dentro de la webserie Cómo conocí a vuestra Amatxu, enmarcada en la campaña global de branded content "Generación de endrinistas" producida por Pacharán Zoco. 
El objetivo fundamental del presente trabajo es detectar y analizar las distintas manifestaciones de la marca que sustenta la acción de branded content en la narración propia de la webserie. Es decir, cómo se percibe, cómo se manifiesta y cómo se interrelaciona la marca con el resto del storytelling, tanto a nivel gráfico como de referencias. De este objetivo inicial surge el objetivo específico de detectar y conocer los recursos más evidentes de la marca a la hora de manifestarse en el seno de la ficción online y detectar similitudes, repeticiones y estilos comunicativos que permiten la implicación de la marca en la ficción. Además, se pretende relacionar la propia acción comunicativa de la marca en la ficción con el resto de recursos empleados por la ésta para promocionar la serie (si existiesen) con el fin de observar si se detecta algún tipo de promoción crossmedia alrededor de la webserie. El último objetivo reside en ofrecer datos empíricos sobre el impacto generado por la webserie en las redes sociales, mediante la recogida de información relativa a la actividad del usuario en las redes sociales (votos favorables, votos negativos, comentarios recibidos, comparticiones realizadas...) para poder hacer una valoración acerca de la capacidad de la webserie y las acciones promocionales que la envuelven para la creación de comunidad online.

La metodología empleada se sustenta en un análisis cualitativo sobre la presencia de la marca tanto a nivel gráfico como verbal, dentro de los dos capítulos que conforman la webserie. En segundo lugar, se registran y analizan el resto de acciones promocionales online creadas alrededor de la webserie, tanto en páginas webs como en redes sociales. Tras identificar las manifestaciones de la marca en la ficción y el resto de recursos empleados en la promoción de la misma, se analiza el despliegue transmedia que ha apoyado a la ficción en sí, mediante el recuento de las interacciones más significativas para la campaña. Todo ello, con el correspondiente análisis previo de las acciones comunicativas de la marca Pacharán Zoco, que delimitan de alguna manera, el tono y el mensaje a perseguir en la acción concreta de Cómo conoci a vuestra Amatxu.

\subsection{Sobre la campaña}

La "Generación de endrinistas" es el eje comunicativo de la campaña de branded content de Pacharán Zoco. El Endrinismo, tal y como ellos mismos lo definen en su web es:

Una corriente de pensamiento y de conducta que se basa en el disfrute de los momentos auténticos y más tradicionales, compartidos con las personas que son importantes para uno. Esta corriente tiene su máxima expresión a la hora de la sobremesa. Es la aceptación de tener una actitud especial frente a la vida. Saboreando lo bueno, compartiéndolo. (...) Un endrinista puedes ser tú o puedo ser yo, puede ser cualquiera... cualquiera alrededor de una mesa junto a su gente, a gusto, disfrutando del buen momento, entendiendo que la sobre mesa es la vida entre comida y comida ${ }^{5}$.

En el seno de una generación que valora la sobremesa como el momento del deleite vital, tanto de la comida como de la familia y amigos, se enmarca el mensaje estratégico: toda sobremesa debe ser acompañada por un Pacharán Zoco. 
La idea es que, mediante el fomento del endrinismo, se devuelvan los buenos momentos, los momentos que importan de verdad, los momentos que se recuerdan. Poco a poco y gracias al estímulo de Pacharán Zoco, que mejora las condiciones para que la gente disfrute de la sobremesa, vuelve a aflorar de forma descentralizada, por toda España, consiguiendo que cada vez más gente disfrute de la sobremesa y de la vida a gusto.

Esta nueva forma de pensar y actuar promovida por Zoco, que no es otra cosa que disfrutar de los momentos más auténticos compartiendo con la gente más allegada, siempre acompañado de un buen pacharán digestivo Zoco, en la sobremesa. Toda la campaña global y el eje estratégico de la marca gira alrededor de potenciar la sobremesa como lugar de disfrute, acompañándolo del consumo de su producto. La marca, para defender su proyecto ha creado un Decálogo del Endrinista y una aplicación para que el público pueda medir su nivel de endrinismo, mediante la cual se pueden conseguir premios.

El Decálogo del Endrinista es sólo la base filosófica, las normas del juego que rigen el eje comunicativo y estratégico de Pacharán Zoco. El línea con este decálogo, se han desarrollado campañas específicas para potenciar el significado de la sobremesa, buscar endrinistas que han sido distribuidas tanto en su web como en los perfiles de Facebook y Twitter de la marca, así como utilizadas en su publicidad convencional (exterior y gráfica):

Imagen 1. Ejemplos de campañas a favor del Decálogo del Endrinista

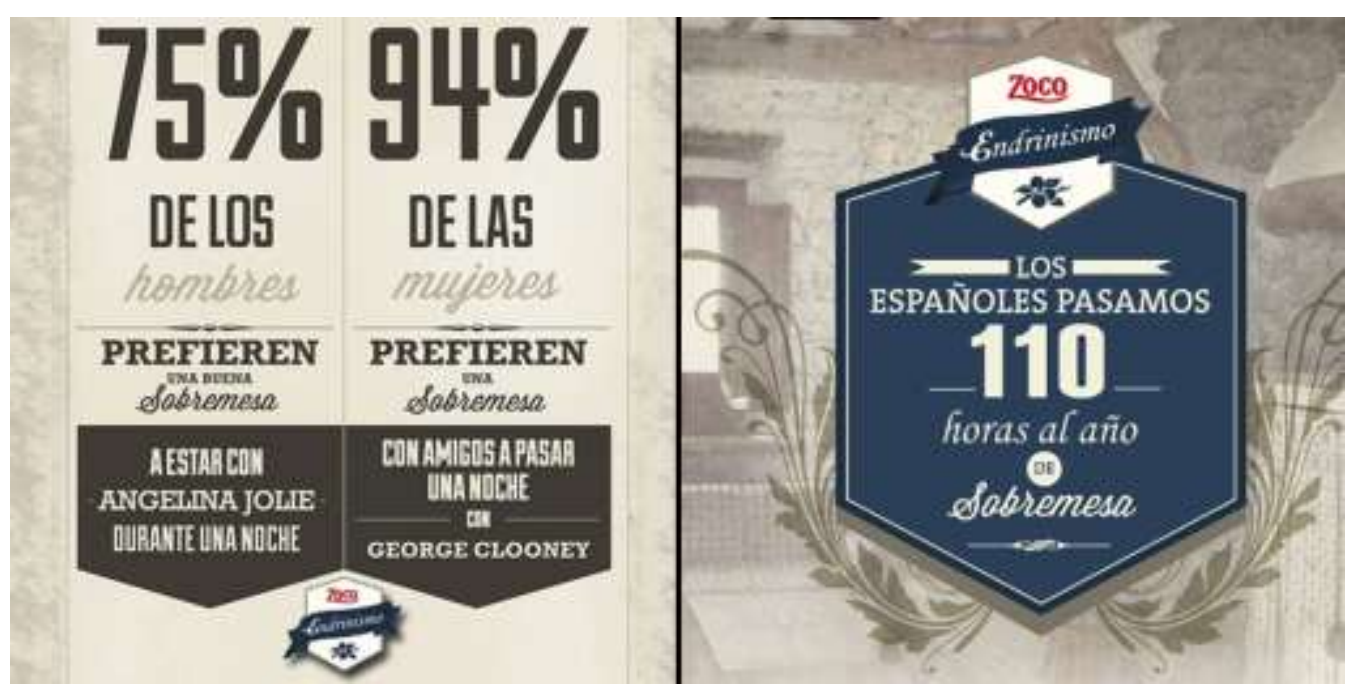

Fuente: https://www.facebook.com/endrinismo

Esta creatividad adherida a la generación de contendido no es un recurso reciente por parte de esta marca. Ya en el año 2006 la marca lanzó el I Concurso de Jóvenes Cocineros del Pacharán Zoco organizado por ARS Publicidad, cuyo objetivo fueron las escuelas de cocina y los futuros chefs como prescriptores. La marca, que contó con el apoyo del Chef Mario Sandoval, pretendía potenciar su imagen corporativa desde dentro, acercándose a los jóvenes promesas de la 
gastronomía española y, a su vez, fomentar nuevos usos de su producto estrella, mediante la transmisión de recetas en las que uno de los ingredientes es el licor de endrinas.

Imagen 2. Ejemplos de anuncio promocional del Concurso Zoco de Jóvenes Cocineros

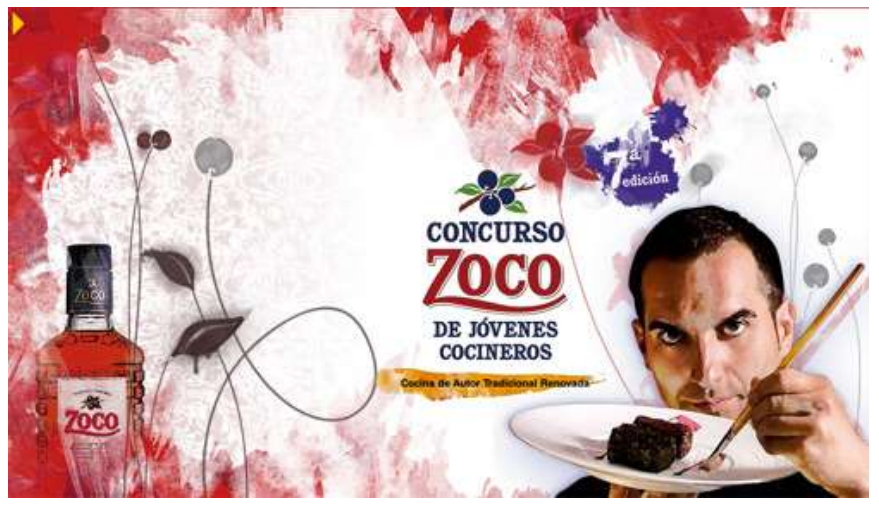

Fuente: elaboración propia a partir de https://www.facebook.com/endrinismo

A lo largo de toda la campaña "soy endrinista" la marca contó con la prescripción del humorista Quequé. La campaña se desarrolló por Bloodymary Comunicación y Social Noise en conjunto y se compuso de diversas piezas de audiovisuales divididos en torno a cinco ejes temáticos: Historias de sobremesa, Fauna endrinista, Rescata a un endrinista, Zococonsejos y Batallitas Zoco. Quequé explicaba qué es el endrinismo mediante distintas situaciones que se viven durante la sobremesa, interpretando a personajes típicos de estas reuniones o dándonos consejos para ser el perfecto endrinista.

El acopio sobre los datos de la difusión de las piezas audiovisuales que iniciaron las campañas audiovisuales de branded content de Pacharán Zoco, arrojan los siguientes resultados:

Tabla 1. Ficha técnica de espacios audiovisuales emitidos por la marca en internet

\begin{tabular}{|l|l|l|l|l|l|}
\cline { 2 - 6 } \multicolumn{1}{c|}{} & $\begin{array}{l}\text { Rescata a un } \\
\text { endrinista }\end{array}$ & Zococonsejos & $\begin{array}{l}\text { Historias } \\
\text { sobremesa }\end{array}$ & $\begin{array}{l}\text { Fauna } \\
\text { Endrinista }\end{array}$ & $\begin{array}{l}\text { Batallitas } \\
\text { Zoco }\end{array}$ \\
\hline Anunciante & Zoco & Zoco & Zoco & Zoco & Zoco \\
\hline Producto & Pacharán & Pacharán Zoco & Pacharán & Pacharán & Pacharán \\
\hline Prescriptor & Quequé & Quequé & Quequé & Quequé & Quequé \\
\hline Año de inicio & 2013 & 2013 & 2013 & 2013 & 2013 \\
\hline No de capítulos & 3 & 4 & 3 & 4 & 5 \\
\hline
\end{tabular}

Fuente: elaboración propia a partir de los datos ofrecidos por el canal de Youtube de la marca

Pacharán Zoco. Disponible en: https://goo.gl/znml6c 
Además, en un intento por dotar a la campaña de un enfoque crossmedia y conseguir el éxito a nivel de marketing online, se lanzaron paralelamente aplicaciones en Facebook para generar interacción entre la audiencia. Así, para apoyar el área temática Batallitas Zoco, se lanzó la aplicación del mismo nombre (https://apps.facebook.com/zocobatallitas/) en Facebook, mediante la cual los usuarios podían contar su historia y compartirla en el canal. Los vídeos del bloque temático Rescata a un endrinista, por su parte, invitaba a las audiencias a interactuar en la red social Facebook con la marca para entrar en el sorteo de una comida entorno al Pacharán Zoco en la que Quequé era el anfitrión.

Podemos observar que los antecedentes de Pacharán Zoco en el marketing de contenidos ya apuntaban maneras en sus inicios. Por ese motivo, no es de extrañar que la marca se atreva a dar un paso más en la unificación del branded content y el mundo audiovisual online, con el lanzamiento de la webserie Cómo conocí a vuestra Amatxu. La creación de esta serie online, propiamente dicha, dista de los productos audiovisuales previos, en los que la marca se decantó por el contenido informativo, documental o humorístico, para lanzarse de lleno al campo de la ficción poniendo de manifiesto las posibilidades de la ficción online en el desarrollo comunicativo de las marcas.

\subsection{La webserie: Cómo conocí a vuestra Amatxu}

Cómo conocí a vuestra Amatxu es el título de la serie de marca creada por Social Noise para Pacharán Zoco. Sus historias son un guiño dirigido especialmente a las áreas clave del producto -Navarra y País Vasco-, donde cuenta la leyenda que no es tarea fácil encontrar una amatxu para tus hijos. Y mucho más si eres Tomás, un consultor informático consumido por un día a día de rutina y reuniones inacabables, que por suerte cuenta con los consejos de Julen, que sabe tomarse las cosas con calma y para el que una sobremesa con sus amigos es sagrada.

Cómo conocí a vuestra Amatxu sustituye a una serie de cortos que protagonizaba el cómico Quequé, quién mediante un monólogo hacía una apología del sentir de la citada generación endrinista y, de paso, se mofaba de la moda del postureo y del estilo hípster.

La finalidad de la webserie no es otra que crear un interesante contenido de marca, concretamente del Grupo Zadibe y su producto Pacharán Zoco a través de un storytelling sobre el estilo de vida de una nueva generación que Pacharán Zoco ha creado: "la generación endrinista", que no es otra cosa que, según el website de Social Noise "el reconocimiento y disfrute de los momentos auténticos con la gente que más nos importa, siendo la sobremesa su máxima expresión”6.

Este formato, ideado y producido por Social Noise, supone un paso adelante en la producción y desarrollo de contenidos recurrentes para Zoco, poniendo en valor todas las características del producto para una nueva generación de endrinistas. El endrinismo es una corriente de pensamiento impulsada por Pacharán Zoco que está basada en el reconocimiento y disfrute de los momentos auténticos con la gente que más nos importa, siendo sobremesa su máxima expresión. 
Tabla 2. Ficha técnica Cómo conoci a vuestra Amatxu

\begin{tabular}{|c|c|}
\hline \multicolumn{2}{|l|}{ Ficha técnica } \\
\hline Anunciante & Grupo Zadibe \\
\hline Producto & Pacharán Zoco \\
\hline Webserie & Cómo conocí a vuestra Amatxu \\
\hline Campaña & La generación endrinista \\
\hline Productora Audiovisual & Visual Noise \\
\hline Año & 2015 \\
\hline Temporadas & 1 \\
\hline Capítulos & 2 \\
\hline
\end{tabular}

Fuente: elaboración propia.

La serie, en el momento en el que se escriben estas líneas, sólo cuenta con dos capítulos, que han sido suficientes para consolidar una audiencia alrededor de la marca, agrupando no sólo a nuevos espectadores, fans de la ficción online, sino también a los antiguos fans de campañas de branded content anteriores, a los verdaderos endrinistas que se han sentido parte de esa nueva generación basada en el la filosofía de los pequeños detalles de la vida que Pacharán Zoco ha sabido definir y ejemplificar a través de su humor y su empeño por fomentar la sobremesa.

Aunque la duración de la webserie es muy corta, se consigue un emplazamiento muy atractivo tanto de la marca (Zoco) como del producto (pacharán) que interactúan armónicamente con las escenas, los personajes y el humor de los diálogos.

Tabla 2. Resumen análisis piezas Cómo conocí a vuestra Amatxu

\begin{tabular}{|l|l|l|}
\hline Análisis piezas & Capítulo 1x01 & Capítulo 1x02 \\
\hline Fecha de emisión & 18 marzo 2015 & 6 abril 2015 \\
\hline Día de estreno/emisión & Miércoles & Lunes \\
\hline Duración & $3: 00$ & $4: 22$ \\
\hline Emplazamiento de la marca $\left(\mathrm{n}^{\circ}\right)^{*}$ & 17 & 23 \\
\hline Menciones a la marca/producto $\left(\mathrm{n}^{\circ}\right)^{* *}$ & 2 & 5 \\
\hline
\end{tabular}

* Se registran todos los emplazamientos en los que aparece identificada la marca en planos diferentes.

**Se registran todas las menciones a la marca o producto específico que representa ("pacharán”).

Fuente: elaboración propia a partir de https://www.youtube.com/user/endrinismo

Tras el análisis de los capítulos y su relación con la marca, observamos que, en una serie de sólo dos capítulos cuya duración no sobrepasa los cuatro minutos y medio, el emplazamiento de la marca es relevante. En el primer capítulo son 17 los casos en los que podemos ver la marca 
gráficamente en planos distintos, elevándose a 23 en el segundo capítulo, en proporción directa a la mayor duración. Sólo en la cabecera de la webserie, ya podemos apreciar su presencia:

Imagen 3. Frame de la cabecera de la serie

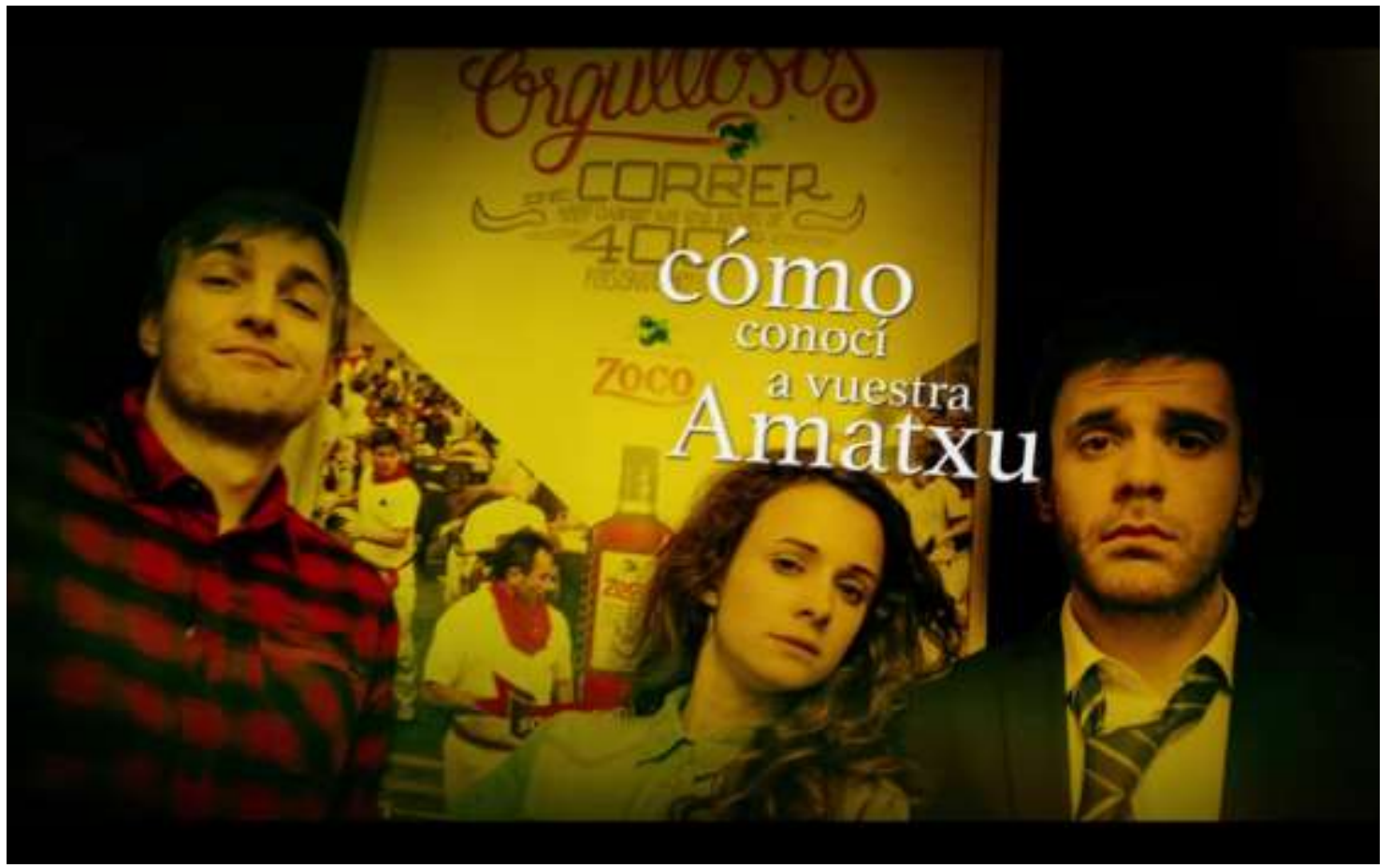

Fuente: https://www.youtube.com/watch?v=bvlUBYUUDkI

A lo largo de los dos capítulos, las referencias gráficas a la marca son más que evidentes, aunque éstas aparecen perfectamente emplazadas en el escenario de la ficción, de forma totalmente cotidiana y sin apenas romper la armonía de las escenas:

Imagen 4. Frames de la serie con emplazamiento del producto

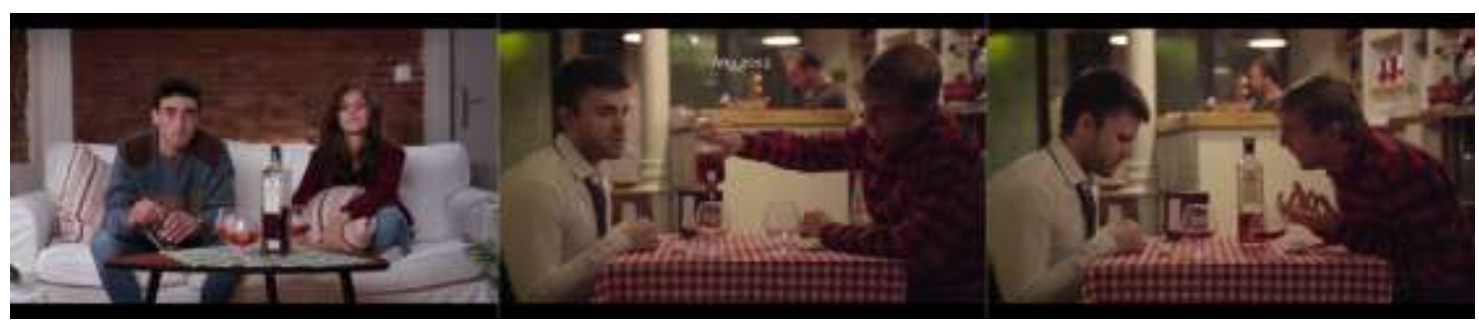

Fuente: elaboración propia a partir de https://www.youtube.com/user/endrinismo

El cierre de cada capítulo nos recuerda, además, quién es la marca que está detrás de la producción mediante un plano sobrio, a modo de firma, cuya única vinculación es la marca, con ausencia de créditos y referencias. 


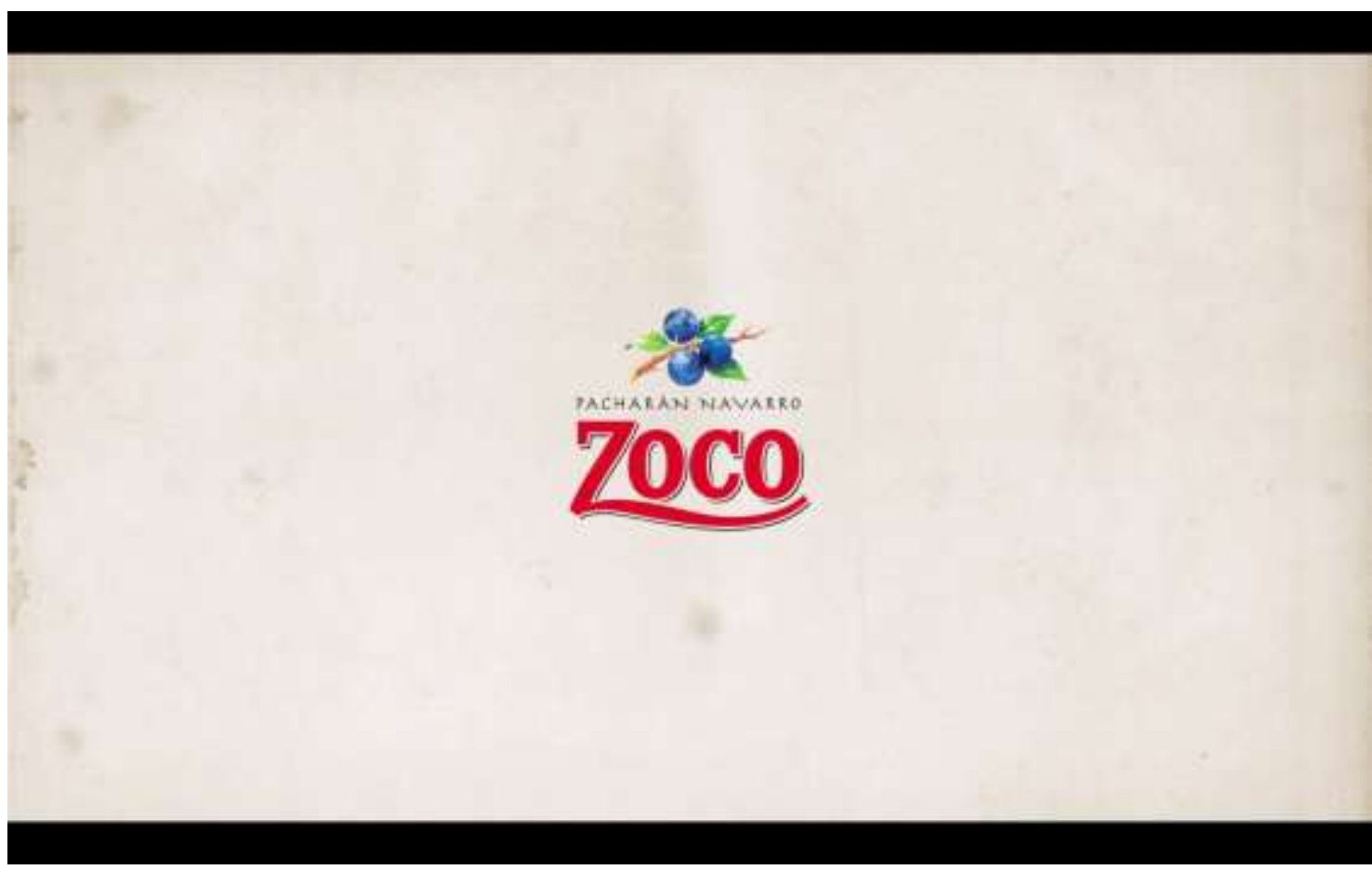

\section{Fuente: https://www.youtube.com/watch?v=bv|UBYUUDkI}

Si hablamos de las menciones verbales a la marca, que son inferiores numéricamente, puesto que se pretende dar más notoriedad a la imagen. No obstante, existen diversos mensajes que nombran explícitamente el producto, en un intento por alinear el estilo y el tono de la webserie a las piezas audiovisuales antecesoras en la estrategia comunicativa de Zoco. No se nombra como tal la marca "Zoco" pero se hace referencia al producto y se acompaña con la imagen de la marca, generando así una vinculación directa entre el producto y el logotipo corporativo:

Protagonista: "El pacharán, me recuerda al día más importante de mi vida".

Protagonista: "Hace veinte años el pacharán emperaba a ser la bebida de moda".

Protagonista: "V uestro tío Julen y yo pasábamos las sobremesas con nuestro pacharán preferido".

Protagonista: "Voy a esperar a que se termine el pacharán".

Camarero: "Venga que os invito a dos pacharanes".

Las posibilidades de transmisión de la imagen gráfica de la marca son logotipo o el propio producto. Ambos aparecen de forma armónica interactuando con los personajes. Como si de un product placement tradicional se tratara, el producto y la marca forman parte del paisaje de la ficción, están completamente integrados y en ningún momento generan distancia con el espectador. Zoco forma parte de la vida de los personajes, pero además, hace referencias directas a la filosofía endrinista y exalta la sobremesa, por ser ésta el concepto sobre el que se han basado el resto de acciones de branded content que ha llevado a cabo históricamente la marca. 
Observamos, pues, que la combinación entre el emplazamiento del producto y las referencias directas a toda su idiosincrasia generan un panorama audiovisual de ficción en el que la marca puede ser entendida como un protagonista más de la historia sin la que la narración no tendría sentido.

Ahora bien, si algo caracteriza al medio online es la posibilidad de compartir y difundir contendidos de forma ilimitada por parte de los espectadores. La interactividad como características integradas en la lógica de internet y las redes sociales genera todo un escenario sobrecomunicativo que acaba beneficiando a la propia marca, que verá crecer exponencialmente su posicionamiento online. En este sentido, recogemos los datos de interactividad relacionados con la serie, que se han recogido de la red social Youtube, plataforma de videoweb en la que se alojan los capítulos de la webserie en cuestión:

Tabla 3. Interactividad de los espectadores frente a la serie

\begin{tabular}{|l|l|l|}
\cline { 2 - 3 } \multicolumn{1}{c|}{} & Capítulo 1x01 & Capítulo 1x02 \\
\hline $\mathrm{N}^{\circ}$ visualizaciones & 174.674 & 174.668 \\
\hline $\mathrm{N}^{\circ}$ me gusta & 91 & 75 \\
\hline $\mathrm{N}^{\circ}$ no me gusta & 21 & 6 \\
\hline $\mathrm{N}^{\circ}$ comentarios & 17 & 7 \\
\hline $\mathrm{N}^{\circ}$ comparticiones & 158 & 70 \\
\hline
\end{tabular}

Fuente: elaboración propia a partir de https://www.youtube.com/user/endrinismo. Fecha de análisis 24 de septiembre de 2015.

En primer lugar debemos destacar la buena acogida que se ha llevado a cabo por parte de las audiencias. El número de visualizaciones es considerable, teniendo en cuenta el carácter reciente de la serie. Además, el número de veces que se ha compartido cada capítulo augura éxito entre las redes sociales, teniendo en cuenta el impacto exponencial que puede tener cada una de estas comparticiones.

A parte de los comentarios, comparticiones y valoraciones que se realizan sobre los capítulos de la ficción por parte de las audiencias y que suponen un incremento considerable en la promoción de la webserie (y, por ende, en la promoción de la marca), se han llevado a cabo estrategias de social media por parte del anunciante, con el objetivo de dar soporte a la propia ficción en sí y contribuir tanto a su promoción como a la generación de comunidad fan en las redes sociales.

Así pues, Zoco lanzó paralelamente a la webserie, la aplicación "Díselo con Zoco"7, recurso en Facebook y Twitter donde los fan page podían elegir "a la amatxu o el aita de sus hijos" y enviarles un mensaje compartiendo la aplicación. De entre todos los participantes, se sorteó un kit endrinista de fin de semana para dos personas, compuesto por una noche de estancia rural con cena y desayuno incluidos y una botella de Pacharán Zoco. Toda esta aplicación acababa llevando al 
usuario a la web de la marca, en una acción interconectada de recursos que facilitaba notablemente la interconectividad del contenido. Estamos, evidentemente, ante una acción crossmedia que permite que el mensaje publicitario se nutra y cruce entre varios medios para darle sentido en su conjunto.

\section{Conclusiones}

En términos globales, podemos decir que la web serie Cómo conocí a vuestra Amatxu responde a la estrategia de difusión característica de las ficciones audiovisuales, aunque adaptada a las especificaciones del medio online y de los nuevos perfiles de las audiencias. Esto permite mantener la fidelidad de la audiencia tanto debido a las ventajas de la serialidad de la ficción como a través de los distintos recursos multimediales puestos en práctica por la propia marca.

Cómo conoci a vuestra Amatxu ha sido construida desde la marca y para la marca, siguiendo el tono comunicativo que venía utilizando la empresa y perfeccionando notablemente su canal comunicativo con acciones audiovisuales previas como Historias de sobremesa, Fauna endrinista y Zococonsejos. A pesar de su carácter reciente y su corta duración (recordemos que sólo se han emitido dos capítulos de la misma) la serie seleccionada ha conseguido posicionarse de forma exitosa entre las webseries online españolas - en especial entre las vinculadas con marcas. Si a ello le sumamos los diálogos sencillos, la corta duración de los episodios y el tono de humor que caracteriza a la webserie (y a las campañas de branded content generales de Zoco) nos encontramos ante un producto audiovisual natural, espontáneo y nada forzado, aspectos que valora positivamente la audiencia a la que va dirigida la serie online.

Si algo evidencia este trabajo es que el branded content como comunicación publicitaria encaja perfectamente en el desarrollo de la ficción online, entendiendo a la marca como sujeto emisor de las piezas. La ficción online acoge en su historia el valor de la marca, ofreciendo a ésta todo un relato audiovisual en el que expresarse, definirse y comunicarse. Se abre, pues, todo un abanico de sinergias y posibilidades entre marcas y ficción online que parece ser, viendo las intenciones de marcas y productoras, que no ha hecho más que empezar.

Además, la trayectoria comunicativa de la marca Pacharán Zoco permite vislumbrar una evolución en la utilización del branded content como recurso comunicativo online. Si bien la marca se inició mediante el lanzamiento de un concurso que fue promocionado y emitido en diferido online (Concurso Zoco de Jóvenes Cocineros), siguió en línea con el lanzamiento de los micro espacios documentales de humor protagonizados por Quequé, en los que siguió afianzando la relación entre el audiovisual online y los conceptos adheridos a Zoco. Ante el éxito in crescendo de las distintas acciones, la marca se ha lanzado a la creación de la webserie objeto de estudio de este trabajo, poniendo de manifiesto una tendencia en comunicación publicitaria que empieza a ser un elemento recurrente para muchas marcas. 
En definitiva, este trabajo ha puesto de manifiesto la tendencia latente que acerca el branded content a las marcas, independientemente de su sector, producto o mercado. La ficción online, unida a la necesidad imperante de las marcas de crear historias en las que se involucre a las audiencias, genera todo un amplio abanico de posibilidades comunicativas que generan valor, construyen a la marca, fidelizan audiencias y, lo más importante, crean un microespacio de diálogo entre emisor y receptor que permite consolidar lazos relacionales entre la corporación y el consumidor.

\section{Referencias bibliográficas}

Bermejo, J. (2008). El receptor publicitario del siglo XXI en el marco de la interactividad: entre el consumer y el prosumer. En M. Pacheco (Coord.). La publicidad en el contexto digital (pp. 49-78). Sevilla: Comunicación Social.

Caro, L. y Selva, D. (2011). Estrategias de convergencia y desintermediación en la difusión del videoclip mediante autocomunicación de masas. Revista Trípodos, Volumen Extra.

Castells, M. (2009). Comunicación y poder. Madrid: Alianza.

Castello, A. y Del Pino, C. (2014). Análisis del branded content en televisión: estudio de casos españoles. Revista de Comunicación de la SEECI, 34, 134-149.

Del Pino, C; Castelló, A y Ramos-Soler, I. (2013). La comunicación en cambio constante. Madrid: Fragua.

Eguizábal, R. (1998). Historia de la publicidad. Madrid: Eresma \& Celeste ediciones.

Hernández , P. (2011). Las Webseries: Evolución y características de la ficción española producida para Internet. Revista Faro, 13.

Jenkins, H. (2007). Nine Propositions Towards a Cultural Theory of Youtube. Confessions of an Aca-Fan. The official weblog of Henry Jenkins. [en línea] Disponible en: http://www.henryjenkins.org /2007/05/9_propositions_towards_a_cultu.html

Jenkins, H. et al. (2009). Confronting the challenges of participatory culture. Media Education for the 21s Century. London: The MIT Press.

Lacalle, Ch. (2011). La ficción interactiva: televisión y web 2.0. Revista Ámbitos, 20, 87-108.

Lloret, N. y Canet, F. (2008). Nuevos escenarios, nuevas formas de expresión narrativa: La Web 2.0 y el lenguaje audiovisual. Revista Hipertext.net, 6 [en línea]. 
Madinabeitia, E. (2010). La publicidad en medios interactivos. En busca de nuevas estrategias.

Telos: Cuadernos de comunicación e innovación, 82, 43-54.

Mateos, S. M. (2013). Museos y Content Marketing. Hacia un nuevo modelo de generación de contenidos culturales. Revista Zer, 18(34), 13-28.

Pérez, J. P. y Gómez, F. J. (2013). Nuevos formatos audiovisuales en Internet: cuando el usuario es quien innova. En M. I. De Salas y E. Mira (Coords.). Prospectivas y tendencias para la comunicación en el siglo XXI (pp. 167-187). Madrid: CEU EDICIONES.

Regueira, J. (2011). Big Brother is dead. El día que el consumidor bizo callar a las marcas. Madrid: Editorial ESIC.

Reinares Lara, P. J.; Reinares Lara, E. M. y Reinares Lara, R. (2007). Valoración de la eficacia de las formas publicitarias no convencionales en la televisión: un estudio exploratorio. En J. C. Ayala Calvo (Coord.), Conocimiento, innovación y emprendedores: camino al futuro (pp. 2294-2307).

Segarra, J. e Hidalgo, T. (2013). Brand content y ficción televisiva. El caso de 'I+B, Ir más a los bares' de Coca Cola. Actas V Congreso Internacional Latina de Comunicación Social. La Laguna, Tenerife: Sociedad Latina de Comunicación. Disponible en: http://www.ull.es/publicaciones/latina/13SLCS/2013_actas/057_Segarra.pdf

VV.AA. (2013). Del branded content al storytelling. Ctrl: control \& strategias, 1, 96-107.

\section{Notas}

${ }^{1}$ Cfr. http://goo.gl//1PNG2

${ }^{2}$ Consultado el día 24 de septiembre de 2015. Disponible en: https://goo.gl/P2cHzH

${ }^{3} \mathrm{Crf:}$ http://goo.gl/VgXVK1

${ }^{4} \mathrm{Crf}:$ http://goo.gl/p6ZBCV

${ }^{5} \mathrm{Crf:}$ http://goo.gl/QOzaEd

${ }^{6} \mathrm{Crf}$ h http://socialnoise.com/project/pacharan-zoco-como-conoci-a-vuestra-amatxu/

${ }^{7} \mathrm{Cfr}$. https://www.facebook.com/diseloconzoco1 


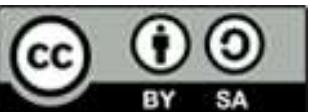

Licencia Creative Commons

Miguel Hernández Communication Journal

mhcj.es

Forma de citar este artículo en las bibliografías

Jesús Segarra-Saavedra, Tatiana Hidalgo-Marí (2016): "La ficción audiovisual y cibernética de los anunciantes. Estudio de caso de Cómo conocí a vuestra Amatxu”, en Miguel Hernández Communication Journal, nº7, páginas 31 a 51. Universidad Miguel Hernández, UMH (ElcheAlicante). Recuperado el _ de de 20__ de: [link del artículo en mhjournal.org] 